Research Article

\title{
Bimetallic CoMo Nanoparticles Supported over Carbon-Zeolite Composites as Dibenzothiophene Hydrodesulfurization Catalyst
}

\author{
Zahra Mohammadian¹, Mohammad H. Peyrovi' ${ }^{1}$ Nastaran Parsafard ${ }^{2, *}$ \\ ${ }^{1}$ Department of Physical and Computational Chemistry, Faculty of Chemistry Science and Petroleum, \\ Shahid Beheshti University, Tehran, Iran. \\ ${ }^{2}$ Department of Applied Chemistry, Kosar University of Bojnord, North Khorasan, Iran.
}

Received: 12 $2^{\text {th }}$ July 2021; Revised: $5^{\text {th }}$ September 2021; Accepted: $6^{\text {th }}$ September 2021

Available online: $7^{\text {th }}$ September 2021; Published regularly: December 2021

\section{Abstract}

Cobalt molybdenum catalysts supported on novel activated carbon-HZSM-5 composites with different mass ratios were prepared by wet-impregnation method and pre-sulfided by $\mathrm{CS}_{2}$. Characterization of these catalysts was done using X-ray powder diffraction, Fourier transform infrared spectroscopy, $\mathrm{N}_{2}$ adsorption-desorption, and scanning electron microscope analytics. Their activity for the hydrodesulfurization reaction of dibenzothiophene was investigated at atmospheric pressure in the temperature range of $250-400{ }^{\circ} \mathrm{C}$ using the fixed-bed reactor with $0.5 \mathrm{~g}$ of each powder and pre-sulfided with $\mathrm{CS}_{2}$. The highest conversion of dibenzothiophene at the temperature range of 300-400 ${ }^{\circ} \mathrm{C}$ was obtained for the CoMo/activated carbon-HZSM-5(1:1) catalyst. The best selectivity for cyclohexylbenzene, which is the dominant product according to gas chromatography results, was obtained at all temperatures using CoMo/activated carbon-HZSM-5(3:1) catalyst.

Copyright (C 2021 by Authors, Published by BCREC Group. This is an open access article under the CC BY-SA License (https://creativecommons.org/licenses/by-sa/4.0).

Keywords: Co-Mo nanoparticles; Hydrodesulfurization; Activated carbon-HZSM-5; Dibenzothiophene

How to Cite: Z. Mohammadian, M.H. Peyrovi, N. Parsafard (2021). Bimetallic CoMo Nanoparticles Supported over Carbon-Zeolite Composites as Dibenzothiophene Hydrodesulfurization Catalyst. Bulletin of Chemical Reaction Engineering \& Catalysis, 16(4), 831-838 (doi:10.9767/bcrec.16.4.11711.831-838)

Permalink/DOI: https://doi.org/10.9767/bcrec.16.4.11711.831-838

\section{Introduction}

Sulfur compounds present in fuels derived from crude oil, which mainly include thiophene, dibenzothiophene and other thiophene-based materials, have been significant sources of environmental pollution due to the conversion to sulfur oxides in the combustion process. They also cause corrosion of connections in chemical reactors. To reduce the emission of these sub-

\section{* Corresponding Author.}

Email: n-parsafard@kub.ac.ir (N. Parsafard);

Tel.: +98 58 32258865; Fax: +98 5832427408 stances due to the detrimental environmental effects, their adverse effects on human health, as well as access to high quality fuels, strict laws have limited the amount of sulfur to less than $10 \mathrm{ppm}$ in refinery products [1-3].

Among the different methods used for this purpose, such as: extractive desulfurization (EDS), oxidative desulfurization (ODS), adsorptive desulfurization (ADS), biodesulfurization (BDS), and the hydrodesulfurization (HDS) method, is preferred, because of its practicality and efficiency compared to other methods in refineries [4]. In this reaction, sulfur is eliminated by using heterogeneous catalysts and the inter- 
action of hydrogen gas and sulfur-containing feed. Since the dependence of this process on the catalytic performance, stability and the crucial role of the catalytic supports in the high dispersion of the active phase, many efforts have been made to develop efficient catalysts to achieve a minimal amount of sulfur [5,6]. Investigation of the support effect is essential to understand their role in the active, the promoter phase dispersion and the types of metalsupport interactions $[7,8]$. Various materials, such as: silica [9], $\mathrm{TiO}_{2}$ [10], $\mathrm{ZrO}_{2}$, carbonaceous and silicate mesoporous, are used as the support in this process [11].

The use of carbon materials because of low cost, high surface area and rich pore structure have been widely reported in adsorption processes [12]. Zeolites are mainly used as support to increase surface area, access to acid/base sites and ease of molecular diffusion into the pores, either alone or as a composite. Recently, the application of composite supports has expanded due to their influential role in improving the performance of catalysts [13]. Wu et al. reported that NiMo/ZSM-5-Kit-6 showed higher yields in the hydrodesulphurization reaction than $\mathrm{NiMo} / \mathrm{Al}_{2} \mathrm{O}_{3}$ [14]. Also Zhang et al. illustrated that nickel-molybdenum supported on ZSM-5-FDU-12 performs better than NiMo/FDU-12 [15]. Parsafard et al. investigated the activity of cobalt-molybdenum impregnated on silicates-HZSM-5 composites, which found CoMo/Kit-6-HZSM-5 have the acceptable performance in the HDS process due to its structural properties [16].

In this work, an attempt is made to prepare the composite catalysts by using the activated carbon due to desirable properties such as costeffectiveness and high surface area, as well as zeolite support for easy access to acidic sites and increasing molecular diffusion. The aim is that hybrid catalysts, in addition to being environmentally friendly, show good performance in the HDS process due to their desirable properties. In this project, novel activated carbonzeolite composites with different weight ratios to investigate the effect of each of them were designed. Cobalt and molybdenum metals are loaded on composites in certain percentages. The reason for this is that their performances evaluated as a function of the reaction temperature and the change in the weight ratio of each catalytic support. The CoMo catalysts were prepared by the co-impregnation method and their activity were investigated in HDS process. It should be added that the powders were identified by various techniques, such as FT-IR, XRD, $\mathrm{N}_{2}$ adsorption-desorption, and
SEM, to determine their geometrical and structural properties.

\section{Materials and Methods}

To prepare composites with different weight ratios by sol-gel method, a specific amount of activated carbon and weighted H-ZSM-5 were mixed and rotated after adding distilled water at $80^{\circ} \mathrm{C}$ until the gel formation [17]. The prepared composites were washed and dried at $100{ }^{\circ} \mathrm{C}$. These composites are symbolized as AC-Z ( $x: y)$ that $x$ and $y$ are the weight ratio of activated carbon and zeolite. Next, to prepare catalysts with $10 \mathrm{wt} \%$ molybdenum and $3 \mathrm{wt} \%$ cobalt, a solution of ammonium heptamolybdate at the specified concentration was prepared and a certain amount of cobalt nitrate salt was weighed and added to the desired composites [16]. Subsequently, by adding distilled water the final solution was stirred until the gel formed. The gel was then dried overnight in an oven at $100{ }^{\circ} \mathrm{C}$ and then calcined for $4 \mathrm{~h}$ up to $300^{\circ} \mathrm{C}$.

\subsection{Catalyst Characterization}

The crystal structure of the desired catalysts was collected by X-ray diffraction (XRD) with an X-PERT diffractometer using $\mathrm{Ni}$ filtered $\mathrm{Cu}-\mathrm{K} \alpha$ radiation at $45 \mathrm{kV}$ and $50 \mathrm{~mA}$ at a scanning speed of $0.06^{\circ} \mathrm{s}^{-1}$. FT-IR spectra were recorded on a BOMEM FT-IR spectrophotometer model Arid-Zone TM, MB series in the range of $400-4000 \mathrm{~cm}^{-1}$. For detection of products, a Gas Chromatography (model 7890), equipped with a flame ionization detector and a split/non-flush input chamber and BP5-type Moon Column (SGA Australia) manufactured by the Ajilien Company (USA) was used. Scanning electron microscope (SEM) images were obtained by a HITACHI S-4160 instrument those catalysts coated with gold and operating at an accelerating voltage of $30 \mathrm{kV}$. Pore size and surface area of catalysts were determined by a Brunauer-Emmett-Teller (BET) method (BELSORP MINI II). The data were obtained at $-196{ }^{\circ} \mathrm{C}$ on a constant-volume adsorption apparatus. Prior to the adsorption-desorption measurements, all samples were degassed at $300{ }^{\circ} \mathrm{C}$ in $\mathrm{N}_{2}$ flow for $3 \mathrm{~h}$.

\subsection{Catalyst Eevaluation}

Hydrodesulphurization of dibenzotiophene (DBT) was performed in a continuous Pyrex fixed-bed micro reactor at atmospheric pressure and temperature range of $250-400{ }^{\circ} \mathrm{C}$. This process was conducted over $0.5 \mathrm{~g}$ of each 
CoMo impregnated catalyst with an inlet gas containing $5 \mathrm{wt} \%$ DBT dissolved in toluene. Before the catalytic test, all catalysts were presulfurized with a solution of $2 \mathrm{wt} \% \mathrm{CS}_{2}$ in cyclohexane with the rate of $2 \mathrm{~mL} \cdot \mathrm{min}^{-1}$ via a syringe pump and $\mathrm{H}_{2}$ flow of $40 \mathrm{~mL} \cdot \mathrm{min}^{-1}$ at 350 ${ }^{\circ} \mathrm{C}$ for $2 \mathrm{~h}$ under atmospheric pressure. Then, the catalytic test was performed in the mentioned temperature range with the same hydrogen and feed flow and the reactor output were recorded by the gas chromatograph (Agilent Technologies 7890A equipped with a flame ionization detector).

\section{Results and discussion}

\subsection{Catalyst Characterization}

Figure 1 shows Fourier transform infrared (FTIR) spectroscopy of the bimetallic catalysts in the range of $400-4000 \mathrm{~cm}^{-1}$. The peaks between 500 and $1085 \mathrm{~cm}^{-1}$ is important for the detection of molybdate. The bands at 900 to $1050 \mathrm{~cm}^{-1}$ and in $800-850 \mathrm{~cm}^{-1}$ range represent $\mathrm{Mo}=\mathrm{O}$-terminal, $\mathrm{Mo}-\mathrm{O}-\mathrm{Mo}$ asymmetric vibrations, and $\mathrm{O}-\mathrm{Mo}-\mathrm{O}$ stretching vibrations. The tetrahedral, octahedral and other poly molybdate structures and the crystalline $\mathrm{MoO}_{3}$ have shown peaks at 930,980 and $580 \mathrm{~cm}^{-1}$. Also, the tetrahedral and octahedral structures of molybdenum species result in bands between $800 \mathrm{~cm}^{-1}$ and $1085 \mathrm{~cm}^{-1}$. Tetrahedral, octahedral and other polyhedral molybdenum vibrations appear in 830-930, 930-990 and 800-860 $\mathrm{cm}^{-1}$, but because of their overlap with HZSM-5 bands, they are difficult to identify [18]. For activated carbon, the presence of peaks at 1650 $\mathrm{cm}^{-1}$ can be attributed to the carboxyl group and the sharp peak at $1450 \mathrm{~cm}^{-1}$ and weak

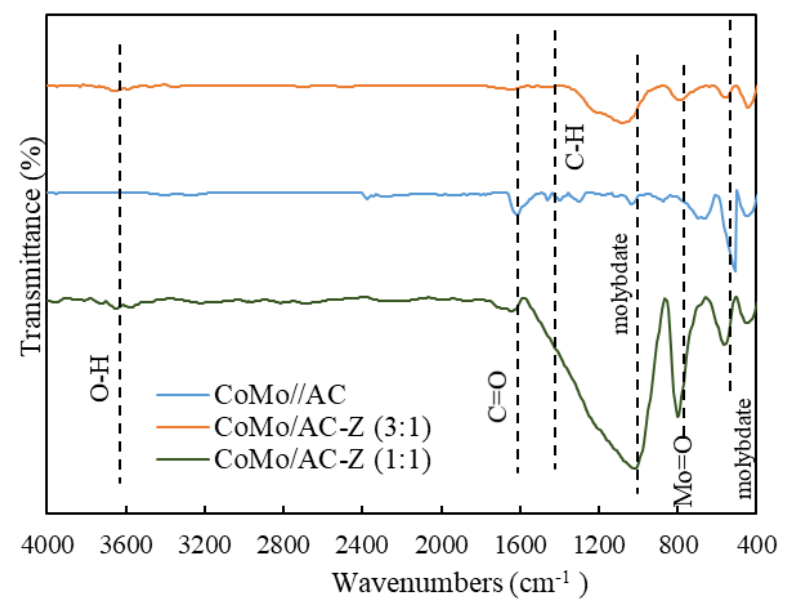

Figure 1. FT-IR spectra of CoMo supported nanoparticles at room temperature with grinding $99 \% \mathrm{KBr}$ and $1 \%$ catalysts. peak at $880 \mathrm{~cm}^{-1}$, respectively, corresponded to symmetric and asymmetric bending vibrations and stretching mode of $\mathrm{C}-\mathrm{H}$ bonds of the aromatic rings in the activated carbon structure [19-22]. In addition, the broad peak at 3400$3600 \mathrm{~cm}^{-1}$ and $1620 \mathrm{~cm}^{-1}$ are indexed to the asymmetry stretching and bending vibrations of the hydroxyl group $(\mathrm{O}-\mathrm{H})$ and, or physisorbed surface water in $\mathrm{KBr}$ [23].

XRD analysis was performed to confirm the presence of activated carbon and HZSM-5 structures after metal impregnation. As shown in Figure 2, in all XRD patterns, the peaks at $2 \theta=6^{\circ}-11^{\circ}$ and $22^{\circ}-25^{\circ}$ show the HZSM-5 phases [20]. The amorphous phase is also observed between $20^{\circ}$ and $30^{\circ}$. The XRD spectra of the CoMo/HZSM-5 catalyst have been reported in our previous work in DBT hydro desulfurization [13]. Compared to pure supports, XRD patterns show that the peak intensities have decreased, expanded, and shifted to higher angles, which could be due to the partial collapse of a lattice on metals (Co and Mo) [27]. The broad diffraction at $2 \theta=15^{\circ}-30^{\circ}$ indexed to the amorphous structure of activated carbon. In addition, broad and weak peak at $2 \theta=40^{\circ}-$ $50^{\circ}$ are related to the graphite structure $[19,28]$. The intensity of these peaks is higher for $\mathrm{CoMo} / \mathrm{AC}-\mathrm{Z}(3: 1)$ catalyst because the weight ratio of activated carbon is higher. In contrast, while the intensity of these peaks decreases for CoMo/AC-Z(1:1).

Figures 3(a-c) show the types of hysteresis loop as well as the pore diameter dispersion. As shown in Figure 3(a), the isotherms related to the composites appear to be the combination of types IV and I, indicating that both micropore and mesopore structures are present. We ob-

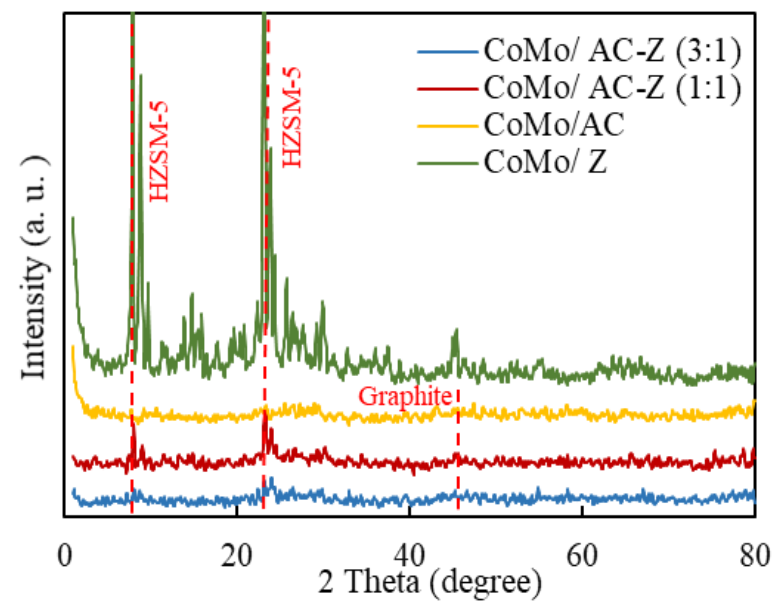

Figure 2. XRD patterns of bimetallic CoMo supported composites with various mass ratios of the $\mathrm{AC}$ and zeolite. 
served type H2 hysteresis loop for the composites that this type is characteristic of solids consisting of particles crossed by nearly cylindrical channels or made by aggregates of spheroidal particles. In this type, pores have the non-uniform size or shape.

Table 1 shows the surface and pore properties of the composites. In agreement with the table data, since the pore size of $\mathrm{CoMo} / \mathrm{AC}-\mathrm{Z}$ (3:1) composite is smaller, it is expected that its specific surface area will be larger. The size of the pores also varies from 2.13 to $2.33 \mathrm{~nm}$, which indicates that according to the IUPAC classification, the prepared composites are mesopores. The pore volume of the composites is al-
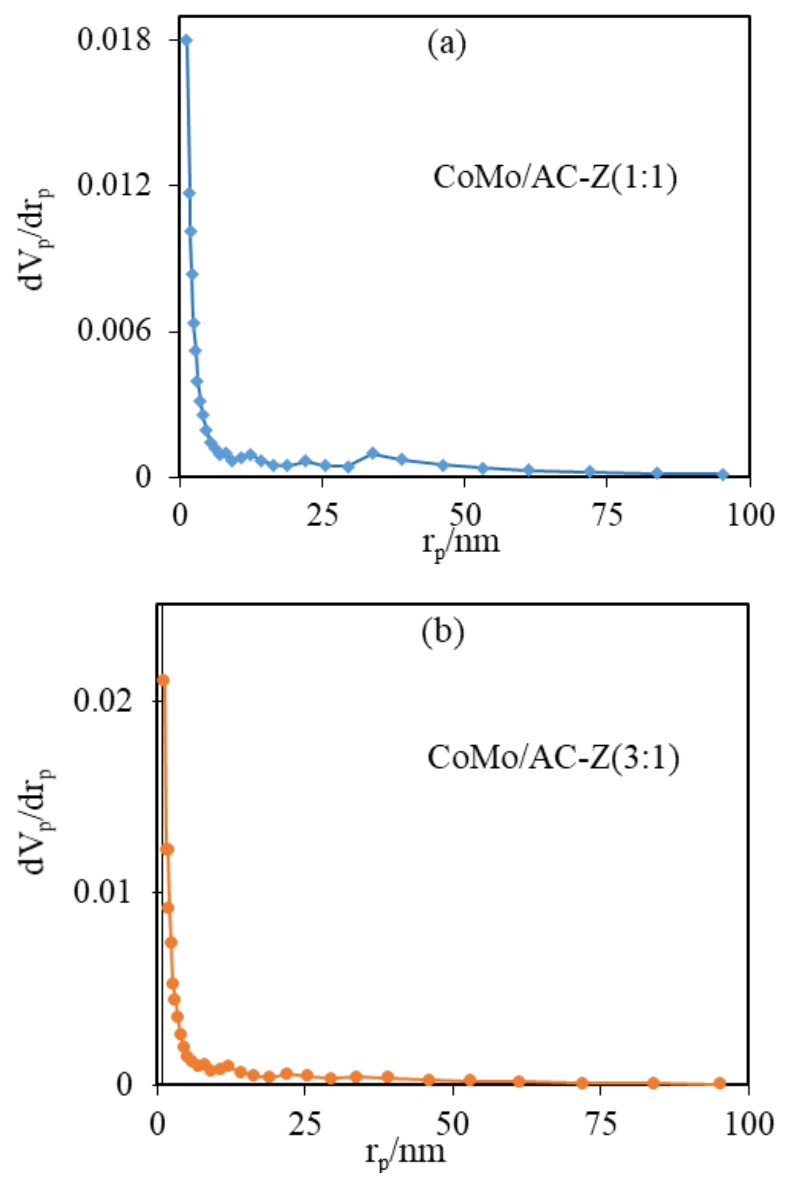

so very close to each other, and unlike $S_{\text {BET, the }}$ surface area obtained by the Langmuir plot for CoMo/AC-Z (1:1) is higher.

Figure 4 shows the morphology of the bimetallic supported on composites taken with the scanning electron microscope. According to SEM images (Figure 4(a)), the activated carbon has the rich-pore structure with many pores arranged in the regular and hexagonal pattern. HZSM-5 also has the hexagonal/cubic morphology that can be seen in Figure 4(b). Unlike activated carbon, whose morphology in composites is unchanged and well visible, but the morphology of the HZSM- 5 is not clearly visible in the composites due to the impregnation of the metals over the composites as well as the calcination, which causes the nanoparticles to aggregate.

\subsection{Activity Test}

The activity results of the catalysts in the temperature range of $250-400{ }^{\circ} \mathrm{C}$ and atmospheric pressure using $0.5 \mathrm{~g}$ of each catalyst are shown in Table 2. The results indicate that the activity of the catalysts is not strongly dependent on the acidic properties of the composites. The reason seems to be the aggregation of $\mathrm{MoS}_{2}$ phases and its transfer from surface to bulk. For the CoMo/AC-Z (3:1) catalyst, activity

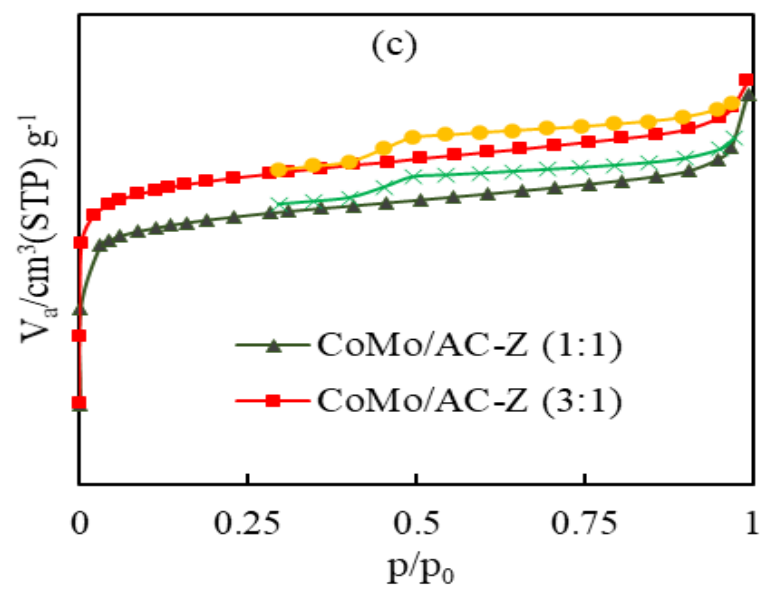

Figure 3. adsorption pore diameter dispersion (BJH plot) (a) CoMo/AC-Z (1:1) (b) CoMo/AC-Z (3:1) and (c) $\mathrm{N}_{2}$ adsorption-desorption isotherms of the bimetallic AC-Z composites.

Table. 1. Surface and pore properties of bimetallic CoMo supported composites.

\begin{tabular}{lccccc}
\hline Catalyst & $S_{\text {BET }}\left(\mathrm{m}^{2} / \mathrm{g}\right)^{\mathrm{a}}$ & $d_{\mathrm{p}}(\mathrm{nm})^{\mathrm{b}}$ & $V_{\mathrm{p}}\left(\mathrm{m}^{3} \cdot \mathrm{g}^{-1}\right)^{\mathrm{c}}$ & $S_{\text {Lang }}\left(\mathrm{m}^{2} / \mathrm{g}\right)^{\mathrm{d}}$ & $A c_{\text {Total }}(\mathrm{mmol} / \mathrm{g})^{\mathrm{e}}$ \\
\hline CoMo/AC-Z (1:1) & 304 & 2.33 & 0.17 & 330 & 2.09 \\
CoMo/AC-Z (3:1) & 346 & 2.13 & 0.18 & 320 & 1.98 \\
\hline
\end{tabular}

a BET surface area by Brunauer-Emmett-Teller method.

b Mean pore diameter by BJH method.

c Total pore volume $\left(\mathrm{p} / \mathrm{p}_{0}=0.990\right)\left(\mathrm{V}_{\mathrm{p}}\right)$ by BET plot.

${ }^{\mathrm{d}}$ Langmuir surface area by Langmuir plot.

e Total acidity by $\mathrm{NH}_{3}$-TPD [25, 27, 28]. 


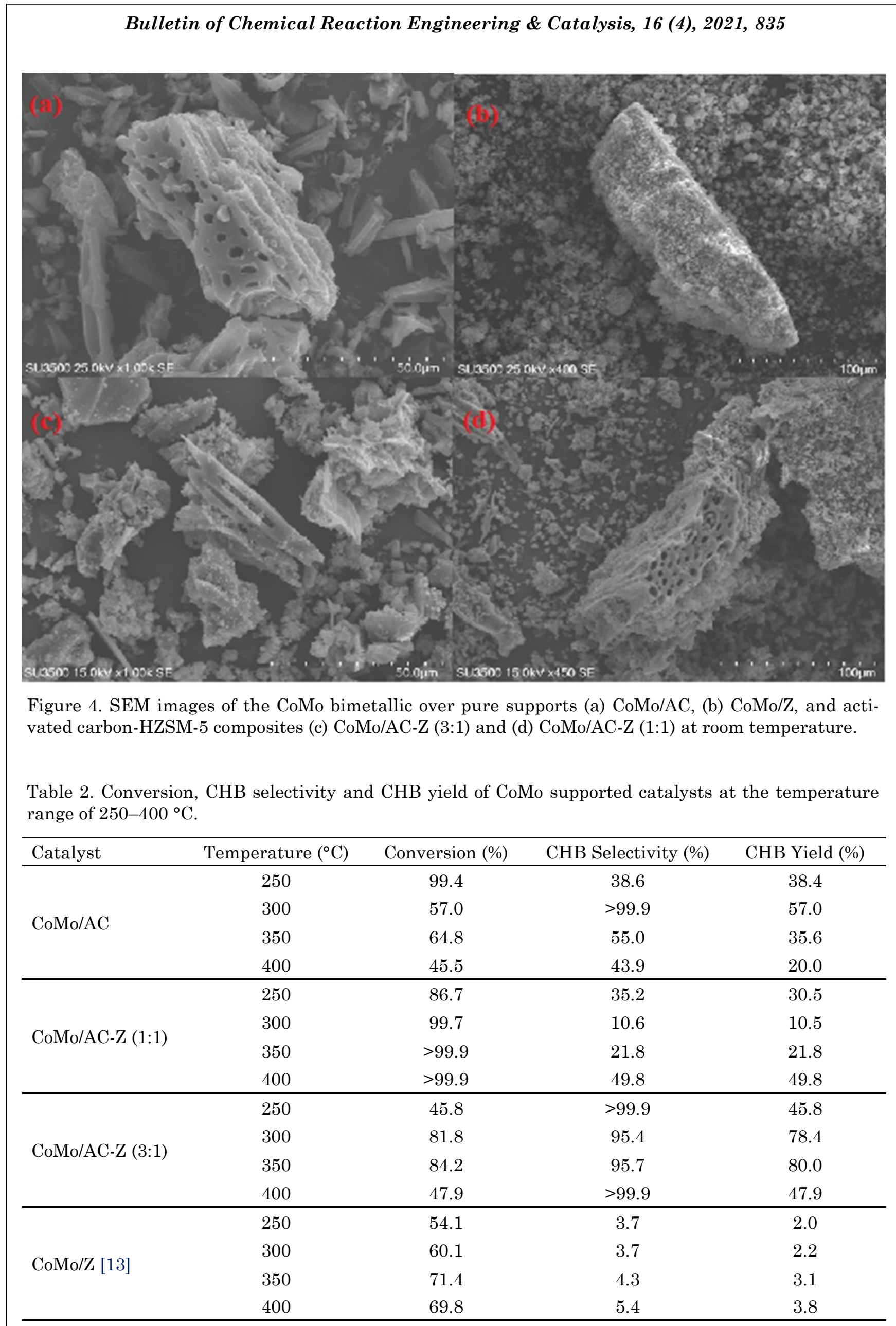


increases and then decreases with increasing reaction temperature. For CoMo/AC-Z (1:1) and $\mathrm{CoMo} / \mathrm{Z}$, as the temperature increases, there is an upward trend in the hydrodesulphurization activity, which seems to increase the partial pressure of the reactants by increasing the temperature, making these materials easy to access for the reaction. With respect to the CoMo-based catalysts that the performance of which was published in the previous report of this group, a similar trend is observed [13]. In addition, the results confirm that the addition of activated carbon increases effectively the selectivity of the prepared composite to the cyclohexyl benzene production.

The CoMo/AC catalyst also exhibits a periodic trend. The highest DBT conversion is obtained for $\mathrm{CoMo} / \mathrm{AC}-\mathrm{Z}(1: 1)$ in the temperature range of $350-400{ }^{\circ} \mathrm{C}$. The results of GC confirm that cyclohexylbenzene is predominant product. The selectivity of the catalysts for this product was calculated. The CoMo/AC-Z(3:1) catalyst has the highest selectivity at all temperatures.

Figure 5(a) shows the effect of weight ratio change of each support on the conversion of dibenzothiophene. According to the figure, the catalytic activity increases with increasing the weight ratio of zeolite in the composite structures. This initial increase in activity seems to be due not to the increase in the metal sulfide dispersion, but to the synergistic effect between the acidic sites and the metal sulfide. However, more activity is due to the higher adsorption of DBT in the pore of zeolites. Nevertheless, as the amount of HZSM-5 and activated carbon changes from the optimum ratio and the weight ratio of zeolite increases, the catalytic activity decreases. The reason for this trend seems to be that zeolites have Brönsted acidic sites, when their number increases and the reaction time passes, these sites are covered with coke, which leads to a decrease in catalytic activity. It should be noted that about the HZSM5 coke formation is less common than other zeolites due to its steric constraints [30]. Also, it should be added that catalytic activity is improved due to the synergistic effect of the activated carbon. It seems that the presence of slitshaped micropores causes the sulfur sink, which improves catalytic performance [31].

Figure 5(b) shows the reaction rate changes due to the increase in reaction temperature. For CoMo/AC-Z (3:1), when the reaction temperature is increased up to $350{ }^{\circ} \mathrm{C}$, the specific rate similarly increases and then the rate decreases. For the CoMo/AC-Z (1:1) and CoMo/Z catalysts, we also see an increasing trend that seems to be due to acidic sites of these catalysts that increases the dispersion of metal sulfides and their easy access [30]. It is assumed that increasing the weight percent of activated carbon up to a ratio of 1:1 (optimized ratio) has a significant effect on the performance of the catalysts by providing sufficient surface area and increasing the active phase dispersion. The CoMo/AC catalyst similarly follows a periodic trend.

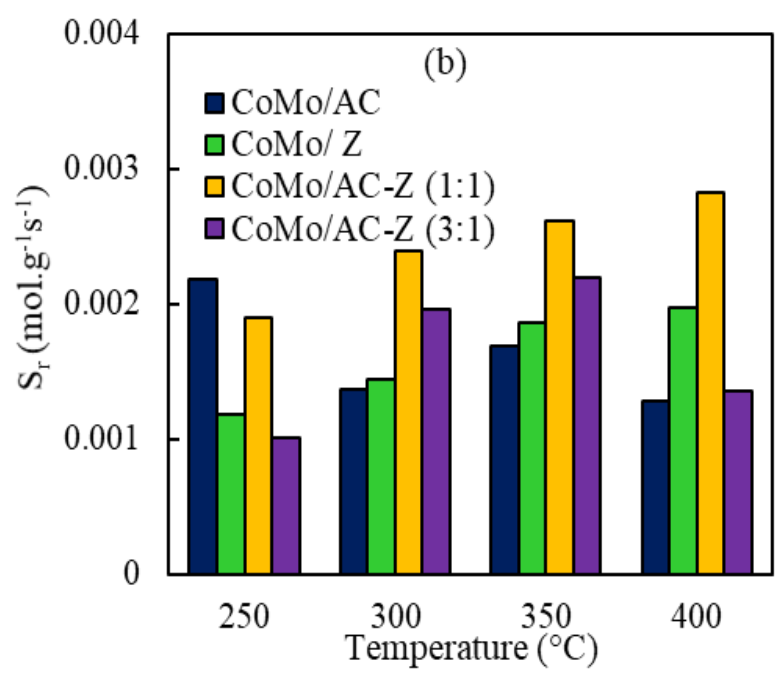

Figure 5. (a) The effect of mass ratio of activated carbon and zeolite on DBT conversion at various temperatures and (b) Specific rate of CoMo supported catalysts as a function of reaction temperature in DBT hydrodesulphurization. 


\section{Conclusions}

In this project, CoMo supported catalysts were successfully prepared. Composites with different weight ratio of activated carbon and H-ZSM-5 zeolite were used as catalyst supports. The performance of these catalysts was investigated in the DBT hydrodesulphurization reaction using fixed-bed reactor. The results of the activity tests confirm that the best conversion of DBT and CHB selectivity were obtained for $\mathrm{CoMo} / \mathrm{AC}-\mathrm{Z} \quad(1: 1) \quad\left(350-400 \quad{ }^{\circ} \mathrm{C}\right) \quad$ and CoMo/AC-Z (3:1) at all temperatures.

\section{Acknowledgements}

The authors gratefully acknowledge from the BCREC Groups for full waiving of the Article Processing Charge (APC) for this article.

\section{References}

[1] Furimsky, E. (2000). Catalytic hydrodeoxygenation. Applied Catalysis A: General, 199, 147-190. DOI: 10.1016/S0926-860X(99)005554

[2] Hernández-Maldonado, A.J., Yang, R.T. (2004). Desulfurization of transportation fuels by adsorption. Catalysis Reviews, 46, 111150. DOI: 10.1081/CR-200032697

[3] Song, S., Yang, X., Wang, B., Zhou, X., Duan, A., Chi, K., Zhao, Z., Xu, C., Chen, Z., Li, J. (2017). Al-modified mesocellular silica foam as a superior catalyst support for dibenzothiophene hydrodesulfurization. Chinese Journal of Catalysis, 38, 1347-1359. DOI: 10.1016/S1872-2067(17)62867-5

[4] Klimov, O.V., Pashigreva, A.V., Fedotov, M.A., Kochubey, D.I., Chesalov, Y.A., Bukhtiyarova, G.A., Noskov, A.S. (2010). Co-Mo catalysts for ultra-deep HDS of diesel fuels prepared via synthesis of bimetallic surface compounds. Journal of Molecular Catalysis A: Chemical, $322, \quad 80-89$. DOI : 10.1016/j.molcata.2010.02.020

[5] Dominguez-Crespo, M.A., Torres-Huerta, A.M., Díaz-García, L., Arce-Estrada, E.M., Ramírez-Meneses, E. (2008). HDS, HDN and HDA activities of nickel-molybdenum catalysts supported on alumina. Fuel Processing Technology, 89, 788-796. DOI: 10.1016/j.fuproc.2008.01.004

[6] Egorova, M., Prins, R. (2006). The role of Ni and Co promoters in the simultaneous HDS of dibenzothiophene and HDN of amines over $\mathrm{Mo} / \mathrm{Y}-\mathrm{Al} 2 \mathrm{O} 3$ catalysts. Journal of Catalysis, 241, 162-172. DOI: 10.1016/j.jcat.2006.04.011
[7] Dhar, G.M., Rana, M.S., Maity, S.K., Srinivas, B.N., Rao, T.P. (2000). Performance of Mo catalysts supported on $\mathrm{TiO}_{2}$-based binary supports for distillate fuel hydroprocessing. In Chemistry of Diesel Fuels, Taylor \& Francis, New York, 157.

[8] Topsøe, H., Clausen, B.S., Massoth, F.E., Anderson, J.R., Boudart, M. (1996). Catalysis science and technology. Hydrotreating Catalysis, 11, 310 .

[9] Polz, J., Zeilinger, H., Müller, B., Knözinger, H. (1989). Hydrogen uptake by $\mathrm{MoS}_{2}$ and sulfided alumina-supported Mo catalysts. Journal of Catalysis, 120, 22-28. DOI: 10.1016/0021-9517(89)90247-9

[10] Maity, S.K., Rana, M.S., Srinivas, B.N., Bej, S.K., Dhar, G.M., Rao, T.P. (2000). Characterization and evaluation of $\mathrm{ZrO}_{2}$ supported hydrotreating catalysts. Journal of Molecular Catalysis A: Chemical, 153, 121-127. DOI: 10.1016/S1381-1169(99)00311-8

[11] Hajjar, Z., Kazemeini, M., Rashidi, A., Soltanali, S. (2018). Hydrodesulfurization catalysts based on carbon nanostructures: A review. Fullerenes, Nanotubes and Carbon Nanostructures, 26, 557-569. DOI: 10.1080/1536383X.2018.1470509

[12] Choi, J.S., Maugé, F., Pichon, C., OlivierFourcade, J., Jumas, J.C., Petit-Clair, C., Uzio, D. (2004). Alumina-supported cobaltmolybdenum sulfide modified by tin via surface organometallic chemistry: application to the simultaneous hydrodesulfurization of thiophenic compounds and the hydrogenation of olefins. Applied Catalysis A: General, 267, 203-216. DOI: 10.1016/j.apcata.2004.03.005

[13] Parsafard, N., Peyrovi, M.H., Parsafard, N. (2017). Influence of HZSM-5 content on behavior of CoMo/HZSM5-HMS composite catalysts in hydrodesulphurization of dibenzothiophene. Journal of the Iranian Chemical Society, 14, 1489-1495. DOI: 10.1007/s13738-0171089-x

[14] Wu, H., Duan, A., Zhao, Z., Li, T., Prins, R., Zhou, X. (2014). Synthesis of NiMo hydrodesulfurization catalyst supported on a composite of nano-sized ZSM-5 zeolite enwrapped with mesoporous KIT-6 material and its high isomerization selectivity. Journal of Catalysis, 317, 303-317. DOI: 10.1016/j.jcat.2014.07.002

[15] Zhang, H., Han, L., Duan, A., Xu, C., Zhao, Z., Wei, Y., Jiang, G., Liu, J., Wang, D., Xia, Z. (2017). Synthesis of micro-mesoporous materials ZSM-5/FDU-12 and the performance of dibenzothiophene hydrodesulfurization. RSC Advances, 7, 28038-28047. DOI: 10.1039/C7RA03679E 
[16] Parsafard, N., Peyrovi, M.H., Mohammadian, Z., Atashi, N. (2020). Activity evaluation of CoMo Nanoparticles supported on mesomicroporous composites in dibenzothiophene hydrodesulphurization. Bulletin of Chemical Reaction Engineering \& Catalysis. 15, 112118. DOI: $10.9767 /$ bcrec.15.1.5556.112-118

[17] Al-Hammadi, S.A., Al-Amer, A.M., Saleh, T.A. (2018). Alumina-carbon nanofiber composite as a support for MoCo catalysts in hydrodesulfurization reactions. Chemical Engineering Journal, 345, 242-251. DOI: 10.1016/j.cej.2018.03.106

[18] Soni, K., Rana, B.S., Sinha, A.K., Bhaumik, A., Nandi, M., Kumar, M., Dhar, G.M. (2009). 3-D ordered mesoporous KIT-6 support for effective hydrodesulfurization catalysts. $A p$ plied Catalysis B: Environmental, 90, 55-63. DOI: 10.1016/j.apcatb.2009.02.010

[19] Mohammadian, Z., Peyrovi, M.H., Parsafard, N. (2018). Catalytic performance and kinetics study over novel Ni/activated carbon-FSM-16 catalysts in the BTX mixture for benzene selective hydrogenation. ChemistrySelect, 3, 12639-12644. DOI: 10.1002/slct.201802760

[20] Baikousi, M., Dimos, K., Bourlinos, A.B., Zbořil, R., Papadas, I., Deligiannakis, Y., Karakassides, M.A. (2012). Surface decoration of carbon nanosheets with aminofunctionalized organosilica nanoparticles. Applied Surface Science, 258, 3703-3709. DOI: 10.1016/j.apsusc.2011.12.010

[21] Veerapandian, M., Lévaray, N., Lee, M.H., Giasson, S., Zhu, X.X. (2015). Glucosamineanchored graphene oxide nanosheets: fabrication, ultraviolet irradiation, and electrochemical properties. ACS Applied Materials \& Interfaces, 7, 14552-14556. DOI: 10.1021/acsami.5b00608

[22] Mojoudi, N., Mirghaffari, N., Soleimani, M., Shariatmadari, H., Belver, C., Bedia, J. (2019). Phenol adsorption on high microporous activated carbons prepared from oily sludge: equilibrium, kinetic and thermodynamic studies. Scientific Reports, 9, 1-12. DOI: $10.1038 / \mathrm{s} 41598-019-55794-4$

[23] Mohammadian, Z., Peyrovi, M.H., Parsafard, N. (2019). Catalytic performance and kinetics study of various carbonaceous supported nickel nanoparticles for atmospheric pressure competitive hydrogenation of benzene. Chemical Physics Letters, 715, 367-374. DOI: 10.1016/j.cplett.2018.12.003
[24] Xia, Y., Mokaya, R. (2004). On the synthesis and characterization of ZSM-5/MCM-48 aluminosilicate composite materials. Journal of Materials Chemistry, 14, 863-870. DOI: 10.1039/B313389C

[25] Parsafard, N., Peyrovi, M.H., Rashidzadeh, M. (2014). n-Heptane isomerization on a new kind of micro/mesoporous catalyst: $\mathrm{Pt}$ supported on HZSM-5/HMS. Microporous and Mesoporous Materials, 200, 190-198. DOI: 10.1016/j.micromeso.2014.08.044

[26] Youming, N., Aiming, S., Xiaoling, W.U., Jianglin, H.U., Tao, L.I., Guangxing, L.I. (2011). Aromatization of methanol over La/Zn/HZSM-5 catalysts. Chinese Journal of Chemical Engineering, 19, 439-445. DOI: 10.1016/S1004-9541(11)60004-9

[27] Parsafard, N., Peyrovi, M.H., Parsafard, N. (2017). Influence of HZSM-5 content on behavior of CoMo/HZSM5-HMS composite catalysts in hydrodesulphurization of dibenzothiophene. Journal of the Iranian Chemical Society, 7, 1489-1495. DOI: 10.1007/s13738-0171089-x

[28] Ganiyu, S.A., Alhooshani, K., Sulaiman, K.O., Qamaruddin, M., Bakare, I.A., Tanimu, A., Saleh, T.A. (2016). Influence of aluminium impregnation on activated carbon for enhanced desulfurization of DBT at ambient temperature: role of surface acidity and textural properties. Chemical Engineering Journal, 303, 489-500. DOI: 10.1007/s13738-0171089-x

[29] Liu, X.Y., Huang, M., Ma, H.L., Zhang, Z.Q., Gao, J.M., Zhu, Y.L., Han, X.J., Guo, X.Y. (2010). Preparation of a carbon-based solid acid catalyst by sulfonating activated carbon in a chemical reduction process. Molecules, $15, \quad 7188-7196$. D O I : 10.3390/molecules 15107188

[30] Welters, W.J.J., De Beer, V.H.J., Van Santen, R.A. (1994). Influence of zeolite acidity on thiophene hydrodesulfurization activity. Applied Catalysis A: General, 119, 253-269. DOI: 10.1016/0926-860X(94)85195-6

[31] Laine, J., Labady, M., Severino, F., Yunes, S. (1997). Sink effect in activated carbonsupported hydrodesulfurization catalysts. Journal of Catalysis, 166(2), 384-287. DOI: 10.1006/jcat.1997.1507 